\title{
Hormone-driven mechanisms in the central nervous system facilitate the analysis of mammalian behaviours
}

\author{
Donald Pfaff \\ Laboratory of Neurobiology and Behaviour, Rockefeller University, 1230 York Avenue, New York, New York 10021, USA \\ (Requests for offprints should be addressed to D Pfaff; Email: pfaff@rockefeller.edu)
}

\begin{abstract}
Hormonal effects on behaviours in animals and humans are now well enough understood for general statements about causal steps to be proposed. Facilitation or repression of a given behaviour by a given hormone can depend on the person's genetic and developmental history, on the temporal and spatial parameters of the hormone's administration, on the hormone's metabolism and on the specific receptor isoform available in a given neuron. The gene for oestrogen receptor-alpha is required for an entire chain of behaviours essential for reproduction, from courtship through maternal behaviours. In order to show that it is possible to use endocrine tools to explain a mammalian behaviour, we analysed lordosis behaviour neuronal circuitry as well as the molecular mechanisms of its facilitation by oestrogens. The functional genomics of oestrogenic effects on lordosis arrange themselves in modules for
\end{abstract}

neuronal Growth, Amplification (by progestins), Preparatory behaviours, Permissive actions by hypothalamic neurons, and Synchronization of mating behaviour with ovulation (GAPPS). A related four-gene micronet involving the amygdala and the paraventricular nucleus of the hypothalamus supports social recognition. Underlying all sociosexual behaviour is the fundamental arousal of brain and behaviour. Elementary arousal depends on a bilateral, bidirectional system universal among mammalian brains, and it can be altered by null deletion of the gene for oestrogen receptor-alpha. Future molecular and biophysical studies will specify how hormone effects in the brain change central nervous system state in such a manner as to alter the frequencies of entire sets of behavioural responses.

Journal of Endocrinology (2005) 184, 447-453

\section{Introduction}

Given the complexity of the mammalian central nervous system (CNS), it has not been surprising that discoveries of detailed mechanisms for mammalian behaviours are difficult to achieve. Whether seeking biophysical or genetic explanations of biologically regulated behaviours in experimental animals or in humans, neurobiologists have, for the most part, been at a loss to meld the overwhelming load of facts about neurons and circuits into integrated theories of how the CNS operates. Hormone-driven behaviours offer an exception to this miserable state of affairs. The strategic advantages of being able to 'triangulate' upon behaviourally relevant neuronal mechanisms by the use of molecular endocrine techniques (in addition to the usual determination of adequate stimulus, permissive environment, etc.) have permitted a remarkably detailed accounting of mechanisms for certain reproductive behaviours.

Therefore, in the first section below, I summarize general statements about broad principles applying to all hormone/behaviour relations. Secondly, I review the best worked-out mechanisms for an individual hormonedriven behaviour. These prove that it is indeed possible to analyse the neural, hormonal and genomic steps involved in producing a mammalian behaviour. Emboldened by success in this endeavour, we have begun to deepen the level of enquiry by reasoning from sex behaviours themselves, to their underlying motivational states, and in turn to the fundamental arousal of the CNS which underlies all behaviours. Finally, I speculate about the likely next steps to be taken in this type of neuroendocrinology.

\section{Current state of knowledge}

\section{General principles of hormone/behaviour relations}

Principles of the phenomena themselves During the past 50 years, a huge body of information has accumulated about hormonal influences on behaviours (Pfaff et al., 2002, a five-volume reference source). I have tried to distil the most 
general principles from this body of work (Pfaff et al. 2004), and I summarize them here in their most abstract form.

First and most important, it is clear that hormones can both facilitate and repress behavioural responses in a strong and reliable manner. One hormone can have many behavioural effects. Conversely, combinations of hormones can be important for influencing an individual behaviour. Finally, it may be a hormone's metabolites which actually constitute the behaviourally active compounds.

In terms of a person's history Hormone effects on a given behaviour can depend on family background, the subject's gender and certain developmental events, especially those occurring during critical periods such as the perinatal period or puberty.

Temporal parameters First, duration of hormone exposure can make a big difference. In some cases, longer is better. In other cases, brief pulses are optimal for behavioural effects. Secondly, hormonal secretions and behavioural responses to them are affected by biological clocks.

Spatial parameters We now know that the effects of a given hormone can be widespread across the body. In some cases, it has been demonstrated that central effects are consonant with peripheral effects to form coordinated, unified mechanisms. Within the CNS, hormones can act at all levels of the neuraxis to exert behavioural effects. The nature of the behavioural effect depends on the site of action.

Genomic mechanisms Studies of mechanisms of hormone effects on behaviour have turned up some surprises. For example, in responsive neurons, rapid hormone effects can facilitate later genomic actions. Furthermore, gene duplication products and splicing products for hormone receptors in the CNS often have different behavioural effects. In all cases, both hormone release and hormone effect on a given behaviour depend upon environmental context.

Evolution Finally, in terms of general statements about hormone/behaviour relations, I note that a large portion of neuroendocrine mechanisms have been conserved as we move from the animal brain into the human brain. As an extension of this statement, it has been argued (Pfaff 1999, Ch 8) that we now understand the essential mechanisms underlying the most primitive form of libido. Consequently, a comprehensive neurochemistry of human sexual function is being developed (Meston \& Frohlich 2000).

\section{Proof that hormone-driven behavioural mechanisms can be demonstrated}

In light of the complexity of the mammalian CNS, is it possible to spell out the mechanisms, neuronal and genetic, for any mammalian behaviour? Yes, with all of the strategic advantages offered by the application of endocrine biochemistry, physiology and molecular endocrine techniques to brain research, we have been able to demonstrate exactly how a simple sex behaviour works.

The primary sex behaviour of female quadrupeds, lordosis, is known to depend on the actions of oestrogens followed by progestins (E plus $\mathrm{P}$ ) in cells within defined neuronal groups in the hypothalamus and midbrain. The neural circuit for lordosis behaviour has been worked out thoroughly (Pfaff 1980). Oestrogen-dependent transcription in ventromedial hypothalamic (VMH) cells allows permissive signals to the midbrain central grey, thus enabling the rest of the circuit to operate (Pfaff 1999).

More generally, an entire chain of behaviours necessary for reproduction depends on the gene product coding for oestrogen receptor-alpha (ER-alpha). Courtship behaviours involve a great amount of locomotion, which is highly sensitive to circulating oestrogens. The effects of oestrogen on running behaviour are abolished by null mutations of ER-alpha but are not affected by null mutations of ER-beta (Ogawa et al. 2003). Then, in addition to being essential for lordosis behaviour itself, the ER-alpha gene is necessary for normal maternal behaviour (Ogawa et al. 1998). Although the evidence is conclusive that a normal ER-alpha gene is needed for a proper sequence of behaviours related to reproduction, we still do not know to what extent these genomic effects are developmental.

The functional genomics of oestrogen-responsive genes provide a theoretical paradigm for linking genes to neural circuits to behaviour. I have proposed (Mong \& Pfaff 2004, upon which paper this section depends) that oestrogen-induced genes are organized in the following modules: growth of hypothalamic neurons; amplification of the oestrogen effect by progesterone; preparative behaviours; permissive actions on sex behaviour circuitry; and synchronization of mating behaviour with ovulation (GAPPS). These modules, described below in capsule form, represent mechanistic routes for CNS management of successful reproduction.

Growth effects in neurons, long before lordosis behaviour is displayed

Growth promotion by oestrogens in VMH neurons, in female rats, follows from the stimulation of synthesis of ribosomal RNA, which precedes the elaboration of dendrites and synapses on VMH neurons observed after hormonal treatment. The earliest oestrogen effect is the increase of transcription of ribosomal RNA (Jones et al. 1990), followed rapidly by morphological effects, including those in the nucleolus itself (Cohen et al. 1984) and a striking elaboration of rough endoplasmic reticulum in the cytoplasm (Cohen \& Pfaff 1981). Catherine Woolley (Woolley \& Cohen 2002) and her colleagues have shown, 
probably consequent to the phenomena above, a stimulatory effect of oestrogen treatment on dendritic growth. In the female rat hypothalamus, Frankfurt (1994) and Flanagan (Flanagan-Cato 2000, Flanagan-Cato et al. 2001) have reported that oestrogens foster dendritic growth and an increased number of synapses (Carrer \& Aoki 1982). Therefore, in VMH cells which control lordosis behaviour circuitry, oestrogens apparently provide the structural basis for increased synaptic activity and, therefore, greater sex-behaviour-facilitating output.

\section{Amplification by progesterone}

Administration of progesterone 24 or $48 \mathrm{~h}$ after oestrogen priming greatly amplifies the effect of oestrogen on mating behaviour. This effect requires the nuclear progesterone receptor (PR), as it disappears after antisense DNA against PR mRNA has been administered onto VMH neurons (Pollio et al. 1993, Ogawa et al. 1994, Mani et al. 1994). It also disappears in PR knockout mice (Lydon et al. 1995). Since PR itself is a transcription factor, its induction by oestrogen might imply that certain downstream genes would, consequently, be upregulated. With molecular probes directed to specific genes, studied primarily in female rats, several transcripts have been revealed as upregulated by progesterone (see Mong \& Pfaff 2004, for references).

\section{Preparations for mating by preceding behaviours}

Analgesia The enkephalin gene is turned on rapidly in female hypothalamic neurons by oestrogens (Romano et al. 1988, Priest et al. 1995, Zhu et al. 2001), within about $30 \mathrm{~min}$, and this is proven by in vitro transcription assays to represent a hormone-facilitated transcriptional facilitation (Vasudevan et al. 2001a). The route of action of the enkephalin gene product upon lordosis would theoretically be indirect, through other behaviours. We propose that, through the reduction of pain, enkephalins help to allow the female to engage in mating behaviour despite the mauling she receives from the male. The strong somatosensory and interoceptive stimuli which ordinarily would be treated by the female as noxious are now tolerable and allow successful mating to proceed (Bodnar et al. 2002). Hypothetically, the ability of oestrogens to turn on genes for opioid receptors as well (Quinones-Jenab et al. 1997) has the potential to multiply the hormone's effect on mating behaviour sequences. Specificity among opioid receptors, as well as neuroanatomical site specificity, is observed in this course of action (Pfaus \& Gorzalka 1987a,b, Pfaus \& Pfaff 1992, Acosta-Martinez \& Etgen 2002). The indirect route of action of this multiplicative set of gene inductions allows the female to participate in reproductive behaviour sequences.

Anxiety reduction The oxytocin gene and the gene for its receptor are both expressed by hypothalamic neurons at higher levels in the presence of oestrogens. The indirect route of action of this multiplicative set of gene inductions on mating behaviour is probably through a behavioural link: anxiety reduction allows courtship and mating. This proposal is consistent with previous formulations: oxytocin has been conceived as protecting instinctive behaviours connected with reproduction, maternity and other social behaviours from the disruptive effects of stress (McCarthy et al. 1991). Indeed, oxytocin has an anxiolytic action in the presence of oestrogens (which presumably elevate the oxytocin receptor gene product) (McCarthy et al. 1996).

Social recognition and aggression The induction of the oxytocin gene by oestrogens is an ER- $\beta$ dependent (Nomura et al. 2002a), behaviourally significant (Krezel et al. 2001) phenomenon. This makes sense, since only ER- $\beta$ gene expression is found in oxytocinergic cells (Shughrue et al. 1997). In turn, oxytocinergic projections to the amygdala are thought to be important for social recognition in mice, which helps to prevent aggression (Insel \& Young 2000, Ferguson et al. 2001, 2002). Thus, the lack of social recognition by ER- $\beta$ knockout mice (Choleris et al. 2003) could explain the hyperaggressiveness displayed by ER- $\beta$ knockout male mice (Nomura et al. 2002b). From these data and inferences, we proposed a four-gene micronet supporting social recognition in the service of reproduction (Choleris et al. 2003).

Permissive actions by hypothalamic neurons for the rest of the lordosis circuit to operate

Noradrenergic (NA) $\alpha-1 b$ receptors are induced (Etgen 2002) by oestrogen treatment in female rats, in VMH neurons which govern the rest of the lordosis behaviour circuit (Kow et al. 1992). NA ascending afferents synapse on VMH neurons, coming in from the ventral NA bundle, which originates in arousal-related neuronal groups A1 and $\mathrm{A} 2$, and signals heightened arousal upon stimulation from the male. In biophysical studies, directly applied NA increases the electrical activity of VMH neurons (Kow et al. 1992). Beginning with either Gq or G11 proteins activating phospholipase C, NA action will produce both diacylglycerol, a PKC activator, and inositol-3-phosphate, which mobilizes intracellular calcium. This signal transduction route is predicted to lead to L-type calcium channel opening, as in the heart, but this needs to be established. The induction of alpha- $1 \mathrm{~b}$ receptors by oestrogen treatment is consistent with the greater electrophysiological effectiveness of NA following oestrogen. Since these VMH neurons are at the top of the lordosis behaviour circuit, the NA effect should foster reproductive behaviour and is known to do so.

Muscarinic receptors responding to the neurotransmitter acetylcholine are also expressed in VMH neurons (Kow et al. 1995). Oestrogen treatment increases their activities, as determined electrophysiologically. Inputs to $\mathrm{VMH}$ 
neurons come from, among other places, the lateral dorsal nucleus of the tegmentum. Neurons there are part of the ascending arousal pathways, and would signal stimulation from the male upon mounting the female. We note that the apparent redundancy between ascending NA and muscarinic cholinergic afferents to the hypothalamus helps to guarantee that the system will not fail, thus exemplifying a design characteristic prominent in brainstem arousal system neurobiology. In any case, inducing muscarinic receptors increases the VMH cellular electrophysiological response to acetylcholine. The enhanced $\mathrm{VMH}$ neuronal output subsequent to the cholinergic action primes lower pathways in the circuit for lordosis behaviour (Menard \& Dohanich 1990).

\section{Synchrony of mating behaviour with ovulation}

Gonadotrophin-releasing hormone (GnRH) The physiological importance of oestrogenic elevation of gonadotrophin-releasing hormone $(\mathrm{GnRH})$ and luteinizing hormone-releasing hormone (LHRH) mRNA levels under positive feedback conditions - as well as elevation of the receptor mRNA for GnRH - would be to synchronize reproductive behaviour with the ovulatory surge of luteinizing hormone (LH). The same GnRH decapeptide which stimulates the ovulatory release of gonadotropins also facilitates mating behaviour (Moss \& McCann 1973, Pfaff 1973). In many small animals, synchrony of sex behaviour with ovulation would be biologically adaptive because it eliminates unnecessary exposure to predation. In this respect, the behavioural effect of this neuropeptide is consonant with its peripheral physiological action.

$\mathrm{GnRH}$ also brings up the unusual case of an individual gene causally related to a human social behaviour. During development in vertebrates ranging from fish to man, $\mathrm{GnRH}$ neurons migrate from their birthplace in the olfactory placode into the brain (Schwanzel-Fukuda \& Pfaff 1989). A human with damage at the Kallmann's syndrome (MacColl et al. 2002) locus on the X chromosome did not fail to express the $\mathrm{GnRH}$ gene in the appropriate neurons. Instead, the neurons failed to migrate out of the olfactory placode (Schwanzel-Fukuda et al. 1989). A single gene for the Kall protein (Legouis et al. 1991, Ballabio \& Camerino 1992) accounts for the deficit. It is the gene for an extracellular matrix protein which is necessary for $\mathrm{GnRH}$ neuronal migration, and which, in fact, decorates the migration route (Dellovade et al. 2003). A striking feature of the phenotype in men is important to note: they have no libido. Here is the causal route. The men have no sexual drive, because they have little testosterone, because they have little LH and follicle-stimulating hormone (FSH) circulating from the pituitary gland, because no GnRH is coming down the portal circulation to the pituitary from the hypothalamus, because there is no GnRH in the hypothalamus, because the GnRH neurons did not migrate during development into the brain, because of a mutation in the gene for the Kall protein. Therefore, we can causally connect, step-by-step, an individual gene to an important human social behaviour, but at least six causal links are required. This causal route illustrates the complexity of gene/behaviour relationships in humans.

\section{Summary}

From this series of individual gene inductions by oestrogens acting in the basal forebrain, and the recounting (above) of downstream genes and their physiological routes of action, there emerges a theoretical molecular 'formula' (GAPPS) which appears to account for some of the causal relations between sex hormones and female sex behaviours (Mong \& Pfaff, 2004). First, there is a hormone-dependent growth response, which permits hormone-facilitated, behaviour-directing hypothalamic neurons a greater range of input/output connections and, thus, physiological power. Secondly, progesterone can amplify the oestrogen effect, in part through the downstream genes listed above. Then, through indirect behavioural means - the reduction of anxiety and a partial analgesia - the female as an organism is prepared for engaging in reproductive behaviour sequences. Here the genes for oxytocin (and its receptor) as well as the genes for the opioid peptide enkephalin (and its receptors) are important. Next, neurotransmitter receptor induction by oestradiol permits the neural circuit for lordosis behaviour to be activated. The noradrenaline $\alpha-1 b$ receptor and the muscarinic acetylcholine receptors are key here, in the ventromedial nucleus of the hypothalamus. Finally, induction of the decapeptide which triggers ovulation, GnRH, as well as its cognate receptor acts to synchronize mating behaviour with ovulation in a biologically adaptive fashion.

\section{Reasoning from individual behaviours to underlying motivational and arousal states}

The explanation of lordosis, summarized in the references above, proved that it is possible to delineate the mechanisms for a mammalian behaviour - a social behaviour at that. However, lordosis is just an individual behaviour and hardly represents a public health problem. The following reasoning led from lordosis behaviour to a deeper set of problems which are connected to a host of medical and public health concerns. The ability of sex hormones to facilitate mating behaviours, when all other experimental conditions are held constant, is proof positive that these hormones elevate sexual motivation (Bodnar et al. 2002). The literature on the theory and experimental analysis of motivation, human and animal, shows that all motivational states are divided into two parts: specific motivations (in our case, affiliative and sexual) and the generalized 
activation of brain and behaviour. This latter concept usually is called 'arousal'. That is, to pursue an analogy with physics, if behaviour were represented as a vector, the incentive would control the angle of the vector, but the level of arousal would determine the amplitude (the length) of the vector.

Therefore, the well-developed neuroendocrine literature on sex behaviour, sexual motivation and sexual arousal can be used as a launching platform for attacking the mechanisms of the deeper neurobiological concept of the arousal of brain and behaviour. Conversely, understanding hormonal and other determinants of arousal will reveal the deepest, most primitive means by which steroids influence specific, biologically adaptive behaviours.

We have used a mathematical/statistical approach to show that a generalized ('global') arousal function affects behaviours in mice (Frohlich et al. 2001, 2002). Then, in order to move beyond an historical false dichotomy in this field ('arousal as a monolithic force, exclusively' versus 'arousal completely fragmented into many subordinate neural states'), we devised a theoretical equation to show CNS arousal as a compound, increasing function of a global arousal force (which accounts for about one-third of the data) supplemented by specific arousal states (Garey et al. 2003). In the mammalian brain, arousal control pathways are always present in the following form: bilateral, bidirectional, universal response-potentiators (BBURP theory) (Pfaff 2005). These primitive pathways constitute the most elementary substrate upon which hormonerelated gene products can act, eventually to influence reproductive and other behaviours. In terms of functional genomics, null mutations of the ER-alpha gene drastically reduced generalized arousal, while null mutations of ER-beta had no significant effect (Garey et al. 2003). Manipulation of a different transcript gives a different set of results. Using locked nucleic acid oligomers to construct antisense-DNA molecules directed against mRNA for prostaglandin D synthase, we microinjected these antisense oligos into the lateral preoptic area and significantly increased measures of arousal (Mong et al. 2003). Thus, we now have the capacity to analyse hormonal and genetic mechanisms of the fundamental, elementary arousal which underlies all mammalian behaviour.

The effects of noradrenaline and histamine to increase the rates of electrical discharge of neurons in the ventromedial nucleus of the hypothalamus (responsible for lordosis behaviour) show examples of 'global arousal'related compounds affecting specific arousal states. In the reverse direction, specific arousal forces can affect global arousal. Oestrogens heighten arousal (Morgan et al. 2004), with the particular behavioural consequence depending on the environmental context. Regarding autonomic arousal, oestrogen treatment effectively destroys cross-correlations among arousal measures, effectively adding to the informational capacity of the system (Stavarache et al. 2005, unpublished observations).

\section{Future perspectives}

Looking forward to the further development of hormone/ behaviour scholarship, at least three perspectives come to mind. First, we certainly can expect to gain extremely detailed mechanistic understanding of hormone actions on neurons and glia (a) at the level of the membrane, (b) in terms of signal transduction routes, and (c) in terms of genomic effects of hormones.

Secondly, these different levels of hormone actions will no longer be seen as exclusive alternatives to each other. Already, we know that membrane-limited actions of oestrogens can potentiate later, transcriptional actions (Vasudevan et al. 2001b), in a manner relevant to the facilitation of lordosis behaviour (Kow \& Pfaff 2005). This type of study is likely to launch a field of work which elucidates how different types of action of a given hormone relate to each other.

Thirdly, there will be a massive change in how hormone actions in the CNS will be interpreted. The neurobiology of the twentieth century could be characterized as a hunt for specificity. The paradigmatic question was this: 'How does this particular stimulus (and no others) evoke this particular response (and no others)?' During the twentyfirst century, we will strive to understand how behaviourally relevant hormone actions in the CNS cause changes in CNS states. These will encompass and facilitate entire classes of responses and be scientifically powerful statements in the sense of explaining whole sets of behaviours efficiently. An early example of this trend can be found in our initial analyses of hormone-influenced arousal mechanisms. One of our own next steps will be to analyse and quantify how global arousal affects specific arousal states and vice versa. I hypothesize that there are quantitative trading relations among arousal mechanisms which are influenced by hormones: sex hormones, stress hormones and thyroid hormones at least. While, for experimental precision and ease of genetic manipulations, these studies must be carried out in mice, they are likely to shed light on neuroendocrine contributions to the formation of human temperaments, long-lasting personality dispositions which underlie many of our biologically regulated behaviours.

\section{Acknowledgements}

It is a pleasure to acknowledge helpful criticisms from Professor Barry Keverne and leadership in the initial experimental work from Dr Jessica Mong. This work was supported by National Institutes of Health grants HD05751 and MH38273.

\section{References}

Acosta-Martinez M \& Etgen AM 2002 Activation of mu-opioid receptors inhibits lordosis behavior in estrogen and progesterone-primed female rats. Hormones and Behaviour 41 88-100. 
Ballabio A \& Camerino G 1992 The gene for X-linked Kallmann syndrome: a human neuronal migration defect. Current Opinion in Genetic Development 2 417-421.

Bodnar R, Commons K \& Pfaff DW 2002 Central Neural States Relating Sex and Pain. Baltimore, MD: Johns Hopkins University Press.

Carrer H \& Aoki A 1982 Ultrastructural changes in the hypothalamic ventromedial nucleus of ovariectomized rats after estrogen treatment. Brain 240 221-233.

Choleris E, Gustafsson JA, Ogawa S \& Pfaff DW 2003 An estrogen-dependent four-gene micronet regulating social recognition: a study with oxytocin and estrogen receptor-alpha and -beta knockout mice. PNAS 100 6192-6197.

Cohen R \& Pfaff DW 1981 Ultrastructure of neurons in the ventromedial nucleus of the hypothalamus in ovariectomized rats with or without estrogen treatment. Cell and Tissue Research 217 451-470.

Cohen R, Chung S \& Pfaff DW 1984 Alteration by estrogen of the nucleoli in nerve cells of the rat hypothalamus. Cell and Tissue Research 235 485-489.

Dellovade T, Hardelin JP, Pfaff DW \& Schwanzel-Fukuda M 2003 Anosmin-I immunoreactivity during embryogenesis in a primitive eutherian mammal. Developmental Brain Research 140 157-167.

Etgen AM 2002 Estrogen Regulation of Neurotransmitter and Growth Factor Signaling in the Brain. Hormones, Brain and Behavior, vol 3, pp 381-440. Eds DW Pfaff, A Arnold, A Etgen, S Fahrbach \& R Rubin. San Diego: Academic Press.

Ferguson JN, Aldag JM, Insel TR \& Young LJ 2001 Oxytocin in the medial amygdala is essential for social recognition in the mouse. Journal of Neuroscience 21 8278-8285.

Ferguson JN, Young LJ \& Insel TR 2002 The neuroendocrine basis of social recognition. Review. Frontiers in Neuroendocrinology 2 200-224.

Flanagan-Cato L 2000 Estrogen-induced remodeling of hypothalamic neural circuitry. Review. Frontiers in Neuroendocrinology 4 309-329.

Flanagan-Cato LM, Calizo LH \& Daniels D 2001 The synaptic organization of $\mathrm{VMH}$ neurons that mediate the effects of estrogen on sexual behavior. Hormones and Behavior 40 178-182.

Frankfurt M 1994 Gonadal steroids and neuronal plasticity: studies in the adult rat hypothalamus. Annals of the New York Academy of Sciences 743 45-60.

Frohlich J, Morgan M, Ogawa S, Burton L \& Pfaff DW 2001 Statistical analysis of measures of arousal in ovariectomized female mice. Hormones and Behavior 39 39-47.

Frohlich J, Morgan M \& Pfaff DW 2002 Statistical analysis of hormonal influences on arousal measures in ovariectomized female mice. Hormones and Behavior 42 414-423.

Garey J, Goodwillie A, Ogawa S \& Pfaff DW 2003 Genetic contributions to generalized arousal of brain and behavior. PNAS 100 11019-11022.

Insel T \& Young L 2000 Neuropeptides and the evolution of social behavior. Review. Current Opinion in Neurobiology 10 784-789.

Jones K, Harrington C \& Pfaff DW 1990 Steroid hormone regulation of ribosomal RNA in rat hypothalamus: early detection using in situ hybridization and precursor-product ribosomal DNA probes. Journal of Neuroscience 10 1513-1521.

Kow L, Weesner G \& Pfaff DW 1992 Alpha 1-adrenergic agonists act on the ventromedial hypothalamus to cause neuronal excitation and lordosis facilitation: electrophysiological and behavioral evidence. Brain Research $\mathbf{5 8 8}$ 237-245.

Kow LM \& Pfaff DW 2005 Rapid membrane actions of estrogens and hypothalamic neurons are effective in facilitating lordosis behavior. PNAS In Press.

Kow LM, Tsai YF \& Pfaff DW 1995 In vitro electro-pharmacological and autoradiographic analyses of muscarinic receptor subtypes in rat hypothalamic ventromedial nucleus: implications for cholinergic regulation of lordosis. Brain Research 694 29-39.
Krezel W, Dupont S, Krust A, Chambon P \& Chapman PF 2001 Increased anxiety and synaptic plasticity in estrogen receptor $\beta$-deficient mice. PNAS 98 12278-12282.

Legouis R, Hardelin JP, Levilliers J, Claverie JM, Compain S, Wunderle V, Millasseau P, Le Paslier D, Cohen D, Caterina D et al. 1991 The candidate gene for the X-linked Kallmann syndrome encodes a protein related to adhesion molecules. Cell 67 423-435.

Lydon JP, DeMayo FJ, Funk CR, Mani SK, Hughes AR, Montgomery CA Jr, Shyamala G, Conneely OM \& O’Malley BW 1995 Mice lacking progesterone receptor exhibit pleiotropic reproductive abnormalities. Genes and Development 9 2266-2278.

MacColl G, Quinton R \& Bouloux PM 2002 GnRH neuronal development - insights into the mechanisms of hypogonadotropic hypogonadism. Trends in Endocrinology and Metabolism 13 112-118.

Mani SK, Blaustein JD, Allen JM, Law SW, O'Malley BW \& Clark JH 1994 Inhibition of rat sexual behavior by antisense oligonucleotides to the progesterone receptor. Endocrinology 135 1409-1414.

McCarthy M, Chung S, Ogawa S \& Pfaff DW 1991 Behavioral effects of oxytocin: is there a unifying principle? In Vasopressin, vol. 208, pp 195-212. Ed JR Jard. New York: Colloque INSERM/John Libbey Eurotext Ltd.

McCarthy MM, McDonald CH, Brooks PJ \& Goldman D 1996 An anxiolytic action of oxytocin is enhanced by estrogen in the mouse. Physiology and Behavior 60 1209-1215.

Menard CS \& Dohanich GP 1990 Physostigmine facilitation of lordosis in naturally cycling female rats. Pharmacology, Biochemistry and Behavior 36 853-858.

Meston CM \& Frohlich PF 2000 The neurobiology of sexual function. Archives of General Psychiatry 57 1012-1030.

Mong JA \& Pfaff DW 2004 Hormonal symphony: steroid orchestration of gene modules for sociosexual behaviors. Molecular Psychiatry 9 550-556.

Mong JA, Devidze N \& Pfaff DW 2003 Estradiol differentially regulates lipocalin-type prostaglandin D synthase transcript levels in the rodent brain: evidence from high-density oligonucleotide arrays and in situ hybridization. PNAS 100 318-323.

Morgan MA, Schulkin J \& Pfaff DW 2004 Estrogens and non-reproductive behaviors related to activity and fear. Neuroscience and Biobehavioral Reviews 28 55-63.

Moss R \& McCann S 1973 Induction of mating behavior in rats by luteinizing hormone-releasing factor. Science 181 177-179.

Nomura M, McKenna E \& Pfaff DW 2002a Estrogen receptor-beta regulates transcript levels for oxytocin and arginine vasopressin in the hypothalamic paraventricular nucleus of male mice. Molecular Brain Research 109 84-94.

Nomura M, Durback L, Chan J, Gustafsson J-A, Smithies O, Korach KS, Pfaff DW \& Ogawa S $2002 b$ Genotype/age interactions on aggressive behavior in gonadally intact estrogen receptor $\beta$ knockout ( $\beta E R K O)$ male mice. Hormones and Behavior 41 288-296.

Ogawa S, Olazabal UE \& Pfaff DW 1994 Effects of intrahypothalamic administration of antisense DNA for progesterone receptor mRNA on reproductive behavior and progesterone receptor immunoreactivity in female rat. Journal of Neuroscience 14 1766-1774.

Ogawa S, Eng V \& Pfaff DW 1998 Roles of estrogen receptor-alpha gene expression in reproduction-related behaviors in female mice. Endocrinology 139 5070-5081.

Ogawa S, Chan J \& Pfaff DW 2003 Estrogen increases locomotor activity in mice through estrogen receptor alpha: specificity for the type of activity. Endocrinology 144 230-239.

Pfaff DW 1973 Luteinizing hormone releasing factor (LRF) potentiates lordosis behavior in hypophysectomized ovariectomized female rats. Science 182 1148-1149.

Pfaff DW 1980 Estrogens and Brain Function: Neural Analysis of a Hormone-Controlled Mammalian Reproductive Behavior. New York: Springer-Verlag. 
Pfaff DW 1999 Drive: Neural and Molecular Mechanisms for Sexual Motivation. Cambridge, MA: MIT Press.

Pfaff DW 2005 Brain Arousal and Information Theory: Neural, Hormonal and Genetic Analyses. Cambridge, MA: Harvard University Press.

Pfaff DW, Arnold A, Etgen A, Fahrbach S \& Rubin R (Eds) 2002 Hormones, Brain, and Behavior, 5 vols. San Diego, CA: Academic Press.

Pfaff DW, Phillips MI \& Rubin R Principles of Hormone/Behavior Relations. San Diego, CA: Academic Press/Elsevier.

Pfaus JG \& Gorzalka BB 1987a Opioids and sexual behavior. Review. Neuroscience and Biobehavioral Reviews 11 1-34.

Pfaus JG \& Gorzalka BB $1987 b$ Selective activation of opioid receptors differentially affects lordosis behavior in female rats. Peptides $\mathbf{8}$ 309-317.

Pfaus JG \& Pfaff DW $1992 \mu-, \delta$ - and $\kappa$-opioid receptor agonists selectively modulate sexual behaviors in the female rat: differential dependence on progesterone. Hormones and Behavior 26 457-473.

Pollio G, Xue P, Zanisi M, Nicolin A \& Maggi A 1993 Antisense oligonucleotide blocks progesterone-induced lordosis behavior in ovariectomized rats. Molecular Brain Research 19 135-139.

Priest CA, Eckersell CB \& Micevych PE 1995 Estrogen regulates preproenkephalin-A mRNA levels in the rat ventromedial nucleus: temporal and cellular aspects. Molecular Brain Research 28 251-262.

Quinones-Jenab V, Jenab S \& Pfaff DW 1997 Estrogen regulation of mu-opioid receptor mRNA in the forebrain of female rats. Molecular Brain Research 47 134-138.

Romano GJ, Harlan RE \& Pfaff DW 1988 Estrogen increases proenkephalin messenger ribonucleic acid levels in the ventromedial hypothalamus of the rat. Molecular Endocrinology 2 1320-1328.
Schwanzel-Fukuda M \& Pfaff DW 1989 Origin of luteinizing hormone-releasing hormone neurons. Nature 338 161-164.

Schwanzel-Fukuda M, Bick D \& Pfaff DW 1989 Luteinizing hormone releasing hormone (LHRH) expressing cells do not migrate normally in an inherited hypogonadal (Kallmann) syndrome. Molecular Brain Research 6 311-326.

Shughrue PJ, Lane MV \& Merchenthaler I 1997 Comparative distribution of estrogen receptor alpha and beta RNA in the rat central nervous system. Journal of Comparative Neurology 388 $507-525$

Vasudevan N, Zhu YS \& Pfaff DW 2001a Crosstalk between oestrogen receptors and thyroid hormone receptor isoforms results in differential regulation of the preproenkephalin gene. Journal of Neuroendocrinology 13 779-790.

Vasudevan N, Kow LM \& Pfaff DW $2001 b$ Early membrane estrogenic effects required for full expression of slower genomic actions in a nerve cell line. PNAS 98 12267-12271.

Woolley CS \& Cohen RS 2002 Sex steroids and neuronal growth in adulthood. In Hormones, Brain and Behavior, vol 4, pp 717-777. Eds DW Pfaff, A Arnold, A Etgen, S Fahrbach \& R Rubin. San Diego, CA: Academic Press.

Zhu Y-S, Cai LQ \& Pfaff DW 2001 Molecular analysis of estrogen induction of preproenkephalin gene expression and its modulation by thyroid hormones. Molecular Brain Research 91 23-33.

Received 12 July 2004

Accepted 16 August 2004 